\title{
Persistent hypoplasia of the lung after repair of congenital diaphragmatic hernia
}

\author{
ALISON HISLOP and LYNNE REID \\ Department of Experimental Pathology, Cardiothoracic Institute, Brompton Hospital, \\ Fulham Road, London SW3 6HP
}

\begin{abstract}
Hislop, Alison and Reid, Lyme (1976). Thorax, 31, 450-455. Persistent hypoplasia of the lung after repair of congenital diaphragmatic hernia. Quantitative analysis has been used to assess growth in a lung from an infant aged $2 \frac{1}{2}$ months in whom a diaphragmatic hernia was repaired at birth. The lungs had been abnormally small at birth but at $2 \frac{1}{2}$ months were of normal volume. Alveoli had multiplied at the normal rate after birth but had not reached the number normal for age. The number per acinus was normal but the alveoli were increased in size, particularly in the left lung. The airway number, and thus alveolar, acinar, and arterial number, were all reduced in both lungs, the ipsilateral being most affected.

The pulmonary blood vessels in both lungs showed an increased muscularity that did not correlate with lung volume or alveolar number, a feature that may have been present at birth.

The degrees of hypoplasia in the two lungs were different at birth and this difference had been maintained. The effect of the disturbance to lung growth on the functioning of the lung is discussed.
\end{abstract}

The lungs of infants born with a congenital diaphragmatic hernia are usually hypoplastic, the ipsilateral lung being the more affected (Areechon and Reid, 1963; Snyder and Greaney, 1965). Quantitative analysis of the bronchi, arteries, and alveoli has confirmed that all are reduced in number in both lungs. Areechon and Reid (1963) found less reduction in the number of airways in the contralateral lung while Kitagawa et al. (1971) found it was similar in both. Both groups of workers found the contralateral lung to be larger and to have more alveoli.

Immediately after repair of the hernia the lungs usually fail to expand to fill the chest but within weeks or months the lung fields appear normal on the chest radiograph. Postoperative studies of lung function after repair have given conflicting results. Chatrath, El Shafie, and Jones (1971) reported in a series of 14 children, aged 6-12 years, that the forced expired volume in one second and the forced vital capacity were significantly below normal while values for lung volume compartments were within normal limits. On the other hand, in 17 children aged 6-19 years, Wohl et al. (1973) found that total lung capacity, vital capacity, and forced expired volume were alb normal. In seven of their cases blood flow waso studied, and in all there was a diminished flow to the side of the hernia; in four, reduced arteriab size was evident radiographically. Since no quantitative pathological studies have been madeं on the lungs after repair, we report the findings. in an infant aged $2 \frac{1}{2}$ months at death in whoms a diaphragmatic hernia was repaired on the first day of life.

\section{CASE REPORT}

A female child, delivered at term and weighing $2730 \mathrm{~g}$, was cyanosed from birth. A chest radiograph showed that the heart and mediastinum $\tilde{S}^{\circ}$ were displaced to the right and the left pleurat cavity was occupied by intestine. At 25 hours ofo age an operation was undertaken for repair of the diaphragmatic hernia. It was found that half to two-thirds of the posterior left diaphragm was? absent. This deficiency was closed by sewing the perirenal fascia to the posterior edge of the diaphragm. The left lung appeared to be smalf but filled the left hemithorax except for the upper quarter. 
A chest radiograph three days after operation showed the left lung to be fully inflated but with diminished vascularity.

After operation the child developed bronchopneumonia and when 11 days old needed artificial respiration. It was not possible to wean her off the respirator at any time.

At 1 month of age cardiac catheterization revealed a raised pulmonary artery pressure of $60 / 20 \mathrm{mmHg}$. The left pulmonary artery was small on the angiogram (Fig. 1) and the pressure was lower in this $(65 \mathrm{mmHg})$ than in the right pulmonary artery $(90 \mathrm{mmHg})$. The ductus arteriosus was not patent but there was a small left-to-right shunt at atrial level. Left ventricular angiography revealed isthmal narrowing more severe than in the normal infant, with a pressure difference of $50 \mathrm{mmHg}$ between the left ventricle and the femoral artery. The child died 10 weeks after operation.

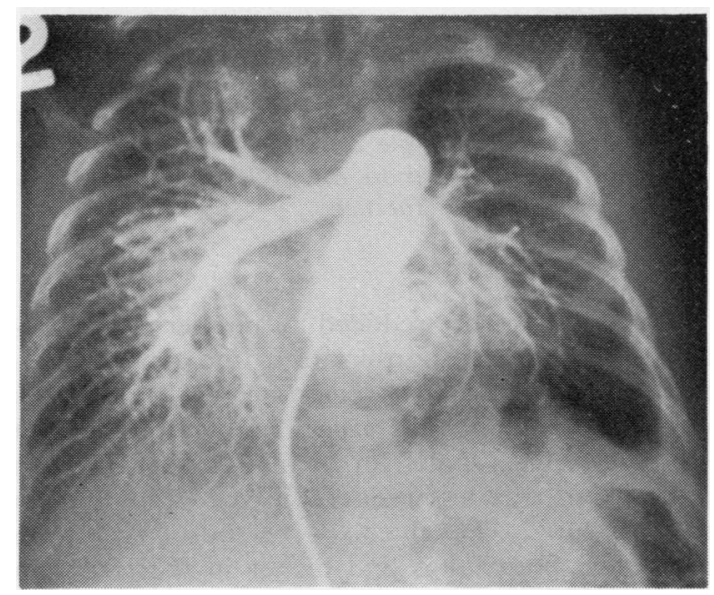

FIG. 1. Pulmonary angiogram at 1 month of age. The right pulmonary artery is normal in size and the peripheral lung is well filled. The left pulmonary artery is small and peripheral filling is poor.

Necropsy revealed multiple defects of the diaphragm; two were present on the right side. There was no herniation through these nor through the repaired left diaphragm. The left lung was small and appeared emphysematous, and the right lung had areas of consolidation and infection with some emphysema. There was a small ventricular defect in the muscular septum. A minor degree of coarctation was present; the ductus arteriosus had closed.

\section{METHODS}

The pulmonary arteries were injected with a mixture of barium sulphate and gelatine at $60^{\circ} \mathrm{C}$ and a water pressure of $100 \mathrm{~cm}$. The lungs were inflated with formol saline until tense. The airways, arteries, and alveoli were studied using standard quantitative techniques (Dunnill, 1962a; Davies and Reid, 1970; Hislop and Reid, 1970).

\section{RESULTS}

MACROSCOPIC APPEARANCE The total lung volume of $250 \mathrm{ml}$ was normal but it was distributed abnormally; the right lung of $150 \mathrm{ml}$ was larger than normal and normal in lobation and shape, while the left lung, of $100 \mathrm{ml}$, was not only smaller than normal but was not divided into upper and lower lobes (Fig. 2); it was evident that underlying air spaces were abnormally large. The cut surface of both lungs showed some patchy areas of consolidation (approximately $10 \%$ of the total volume) and emphysema.

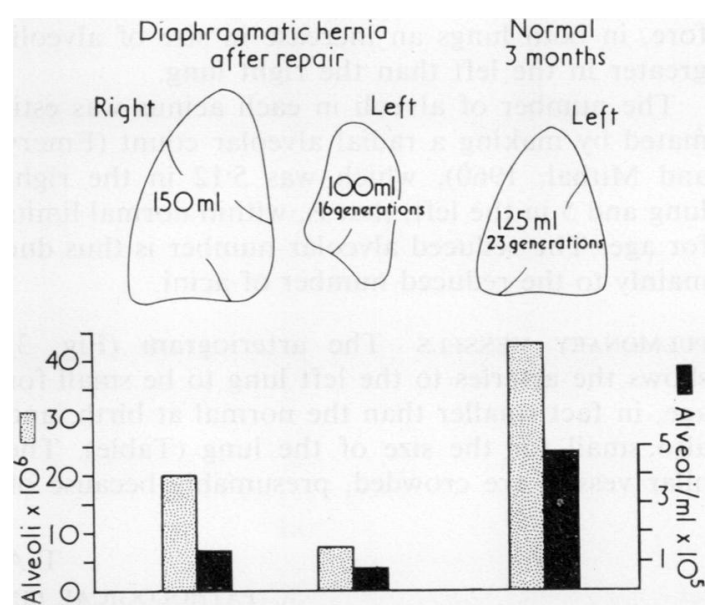

FIG. 2. Diagram illustrating the quantitative findings in the airways and alveoli.

Macroscopic point-counting showed the alveolar region to be $93 \%$ of the right lung volume and $95 \%$ of the left, figures on the high side of normal.

AIRWAYS The number of airway generations along an axial pathway of the posterior basal segment of the left lung was counted after dissection and by tracing serial sections. The total number 
to the level of the terminal bronchiolus was 16 , the expected number being 23 . There were 11 generations of bronchi-that is, airways with cartilage-and five bronchioli, a proportion of each type of airway within the normal range.

ALVEOLI Microscopically the alveoli of the left lung were large and smooth in outline and some had fibrotic walls. Those of the right lung were smaller and more complex in outline, and there were some areas of intra-alveolar oedema. Microscopic point-counting showed that in both lungs the alveolar air occupied a greater proportion of the total lung volume than normal. Total alveolar number was reduced in both lungs, 7.67 million in the left lung and 20.03 million in the right lung (Fig. 2). At 3 months of age the normal number for one lung has been reported as between 37.5 and 43 million (Dunnill, 1962b).

Alveolar size can be assessed from the number of alveoli per millilitre of fixed tissue. In the normal, at the age of this child, 482530 alveoli per $\mathrm{ml}$ of fixed tissue have been reported while, in this case, in the right lung there were only 143619 and in the left lung 80780 . There is, therefore, in both lungs an increase in size of alveoli, greater in the left than the right lung.

The number of alveoli in each acinus was estimated by making a radial alveolar count (Emery and Mithal, 1960), which was 5.12 in the right lung and 5 in the left, that is, within normal limits for age. The reduced alveolar number is thus due mainly to the reduced number of acini.

PULMONARY VESSELS The arteriogram (Fig. 3) shows the arteries to the left lung to be small for age, in fact smaller than the normal at birth, and also small for the size of the lung (Table). The hilar vessels are crowded, presumably because of compression during intrauterine life. The vessel $\overrightarrow{\vec{\delta}}$ of the right lung are normal in size for age, and some small acinar vessels are already present.

In both lungs the vessels within the acinus werêe reduced in size, being smaller in the left than the right lung.

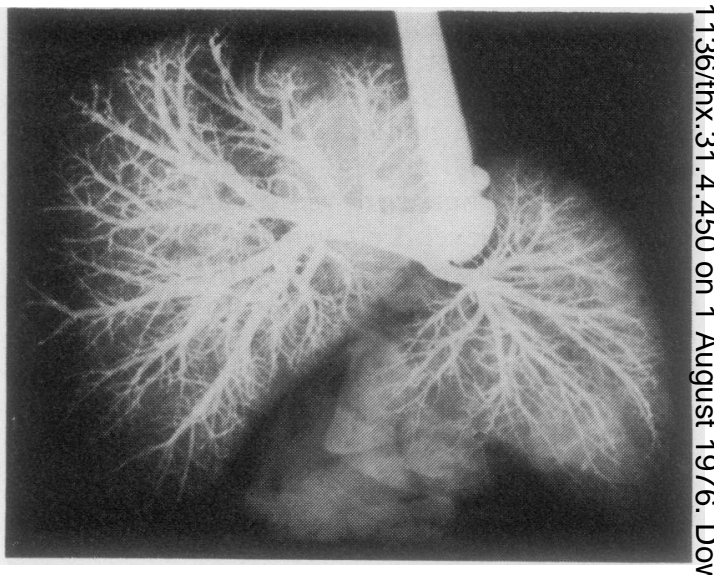

FIG. 3. Postmortem arteriogram of both lungs. The left lung is small and the arteries are reduced in size and number compared to the right lung which has normal sized arteries for age.

The arteries were reduced in number in the pre $\frac{\text { F }}{0}$ acinar region but appropriate to the airway num ber. In the intra-acinar region arteries and alveolह were counted per unit area (Table). Each countw was reduced in both lungs in comparison with normal but was less reduced in the right than in?. the left lung. The alveoli were thus larger than normal in both lungs and bigger in the left than

T A B L E

PATHOLOGICAL FINDINGS IN THE LUNGS

\begin{tabular}{|c|c|c|c|c|}
\hline & \multicolumn{2}{|c|}{ Congenital Diaphragmatic Hernia } & \multicolumn{2}{|c|}{ Left Lung } \\
\hline & R. Lung & L. Lung & Normal $^{1}$ 3-day & Normal $^{1}$ 10-mth \\
\hline $\begin{array}{l}\text { Hilar pulmonary artery diameter }(\mathrm{mm}) \\
\text { Arteries } / \mathrm{cm}^{2} \\
\text { Alveoli/cm } \\
\text { Smallest muscular artery }(\mu \mathrm{m}) \\
\text { Range partially muscular arteries }(\mu \mathrm{m}) \\
\text { Largest non-muscular artery }(\mu \mathrm{m}) \\
\text { Diameter vessels, with respiratory bronchioli }(\mu \mathrm{m}) \\
\text { Structure with respiratory bronchioli } \\
\text { Percentage wall thickness } \\
\text { Vessels } 50-100 \mu \mathrm{m} \\
400-500 \mu \mathrm{m}\end{array}$ & $\begin{array}{l}7 \\
326 \\
3877 \\
22 \\
28-72 \\
22 \\
97 \\
\mathrm{M} \\
9 \cdot 5 \\
6 \cdot 1\end{array}$ & $\begin{array}{l}3 \\
264 \\
2698 \\
41 \\
31-66 \\
44 \\
82 \\
M \\
9 \cdot 4 \\
6 \cdot 2\end{array}$ & $\begin{array}{l}5 \\
874 \\
8820 \\
120 \\
40-180 \\
152 \\
93 \\
\text { PM } \\
6.0 \\
3.9\end{array}$ & $\begin{array}{c}9 \\
847 \\
10758 \\
112 \\
55-220 \\
125 \\
184 \\
\text { PM } \\
\\
\text { NM } \\
2 \cdot 2\end{array}$ \\
\hline $\begin{array}{l}\text { 1Normal figures (Hislop and Reid, 1973; Hislop, } 19 \\
\text { M= Muscular. } \\
\text { PM= Partially muscular. } \\
\text { NM = Non-muscular. }\end{array}$ & & & & \\
\hline
\end{tabular}


in the right lung. The ratio of alveoli to arteries was normal in both lungs, being 10.22 in the left and 11.91 in the right. This suggests that the number of arteries in each acinus was appropriate to the alveolar number.

A study of arterial structure showed the vessels to be more muscular than normal (Table). In both lungs, muscle extended into smaller vessels than normal and also further to the periphery, there being muscular arteries accompanying alveolar ducts while in the normal at this age such arteries do not extend much beyond the terminal bronchiolus (Hislop and Reid, 1973).

Arterial wall thickness, as related to artery diameter, was similar in both lungs and was higher than the normal wall thickness at birth (Hislop and Reid, 1972). In the normal at the age of this patient, the wall thickness would already be reduced almost to adult level and muscle would not be present in such small vessels (Hislop and Reid, 1973).

There was an increase in vein wall thickness and in the amount of elastic in their walls.

\section{SUMMARY OF RESULTS}

In this patient both lungs were emphysematous, the alveoli being larger in the left than in the right lung. Both lungs were hypoplastic with too few alveoli. Although total lung volume was normal, the right lung was larger and the left smaller than normal. The number of airway branches was fewer than normal and hence the number of acini. The number of preacinar arterial branches was less than normal but appropriate to airway number. Within each acinus the number and the ratio of alveolar and arterial number was normal; the arteries and veins were abnormally muscular, assessed by increase in wall thickness and by extension of muscle into smaller vessels than normal.

\section{DISCUSSION}

In this case it can be presumed that the lungs were abnormal at birth. By comparing the findings in this patient, $2 \frac{1}{2}$ months after repair, with those found in patients dying at birth, some comment may be possible on the effect of $2 \frac{1}{2}$ months' growth during which the thoracic volume available for each lung has been normal, though the conditions for growth were not normal.

In this infant the normal total lung volume for age had been reached in the $2 \frac{1}{2}$ months of life. At birth this was less than normal since one lung was seen to be very small, and we know from previous cases that both lungs are affected; for example, in one case, total lung volume was only one-third of the normal at birth (Kitagawa et al., 1971). In the present case at birth the left lung was smaller than the right, a difference maintained, although less marked, until death. The left lung had increased in volume relatively more than the right but had still not reached the normal volume for age. The small size at birth does not represent compression of a lung of normal volume but a lung that contains too little tissue, and the increase in alveolar size had probably reached a maximum for the lung tissue present. It is probable that as the alveolar number in the left lung increased, the lung would reach normal volume. The right lung, having more tissue at birth, had increased to a volume greater than normal, a compensatory increase associated with the small size of the left lung. A similar increase has been seen in the right lung in a case with a congenital hypoplastic left lung (Henderson, Hislop, and Reid, 1971).

Since airway development is complete in the normal fetus by 16 weeks' gestation (Bucher and Reid, 1961), it seems unlikely that there would be any new growth of airways after birth, and none was evident in the present case.

Alveoli develop mainly after birth. In the normal at birth a total of 20 million has been reported (Dunnill, 1962b), and by 10 weeks about 60 million would be expected, the adult number being 300 million (Weibel, 1963). In a case of congenital diaphragmatic hernia at birth the total number of alveoli in both lungs was only $6 \frac{1}{2}$ million and was associated with a reduction in acinar number (Kitagawa et al., 1971). Alveoli were normally differentiated, however, and the number per acinus was normal. It seems that after correction the alveoli multiply relatively normally since in the present case the radial count of alveoli per acinus had increased above birth number and was normal; while infection had not prevented multiplication there has been no extra multiplication to make up the reduced number. In only a few cases has an increase in alveolar number per acinus been seen and these were cases of polyalveolar lobe (Hislop and Reid, 1970) and a case of agenesis of one lung (Ryland and Reid, 1971). The increased space after repair in the case described allowed the lungs to expand after birth and they have done this by increasing alveolar size while multiplying normally. Experimental studies after pneumonectomy in rats of 
all ages have shown an increase in alveolar size, not number (Buhain and Brody, 1972). In this case, in addition to the increase in alveolar size, there may have been air trapping, possibly due to overdistension caused by the use of the ventilator. The infant was also given steroids. The effect of these on alveolar multiplication is unknown though they hasten maturation of the surfactant system in utero (Liggins and Howie, 1972).

In the normal infant in the first two months after birth, the change in the arteries in the preacinar region is concerned with structure and in the acinar region with multiplication. In both regions in the normal infant there is a drop in wall thickness after birth (Hislop and Reid, 1973) as the high vascular resistance of fetal life disappears and the flow to the lung increases. In this case the walls of the pulmonary arteries were thicker than are normally found during fetal life (Hislop and Reid, 1972). There had apparently been no drop in wall thickness after birth and perhaps no normal fall in pulmonary artery pressure. There was no anatomical change in the heart or great vessels to explain this. A small shunt at atrial level was demonstrated at 1 month of age but this would seem an insufficient explanation for such a marked degree of muscle increase; the foramen ovale was closed at death. The ductus arteriosus had closed by 1 month, and during life no shunt was demonstrated through the small ventricular septal defect found at necropsy. The coarctation would not lead to an increase in pressure in the lungs since the ductus was not patent. There was no cardiac cause for the persistence of pulmonary hypertension and it may have been of pulmonary origin. The increase was probably prenatal since a similar increase in wall thickness was found in a case of congenital diaphragmatic hernia studied at birth (Kitagawa et al., 1971).

At cardiac catheterization the pulmonary arterial pressurc was greater in the right than in the left lung, although the left lung was the more hypoplastic; but while wall thickness of the arteries was little different in the two lungs, muscle in the right lung had extended into smaller vessels. This feature probably developed after birth.

The number of arteries in the alveolar region was normal for the number of alveoli in both lungs. In the left lung hilar and peripheral vessels were reduced in size for the lung volume and the age of the child; the total number of arteries was reduced. This may be the cause of the reduction in perfusion to the side of the hernia noted by $\overrightarrow{\vec{s}}$ Wohl et al. (1973). The proximal vessels in theo right lung were of normal diameter for age though음 there was a reduction in the number of arteries $\overline{\frac{\rho}{5}}$

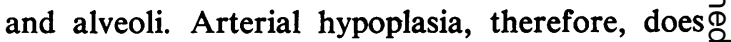
not necessarily lead to a reduction in size of the proximal artery.

All fatal cases of congenital diaphragmatic. $\vec{\circ}$ hernia studied have shown a disturbance of lung $\vec{\omega}$ growth. The surgical reports, postoperative radio- $\rho$ graphs, and recent function studies suggest that, $\vec{x}$ while the degree of damage may vary, all cases will have some degree of impairment of lung growth. The findings in this case support the view: that successful repair will not result in normalo alveolar number and surface area (Berdon, Bakero and Amour, 1968).

The fewer, larger, smooth-walled alveoli and $>$ a reduced number of small arteries will lead to aco reduction in the number of capillaries. In addition, in this case and possibly others, there are $\vec{\oplus}$ primary abnormalities in the arterial system, extreme hypoplasia of the artery to and within one lung, and increased muscularity and pulmonaryo hypertension. It may be that the last is not the usual finding and it may have led to the earlyo death.

We thank Dr. C. L. Berry for allowing us to studyö this specimen.

\section{REFERENCES}

Areechon, W. and Reid, L. (1963). Hypoplasia of lung with congenital diaphragmatic hernia. British Medical Journal, 1, 230.

Berdon, W. E., Baker, D. H., and Amour, R. (1968). The role of pulmonary hypoplasia in the prog- 3 nosis of newborn infants with diaphragmatic hernia and eventration. American Journal of을 Roentgenology, Radiation Therapy and Nuclear $>$ Medicine, 103, 413.

Bucher, U. and Reid, L. (1961). Development of the intrasegmental bronchial tree: the pattern of $\sigma$ branching and development of cartilage at various $\mathrm{N}$ stages of intra-uterine life. Thorax, 16, 207.

Buhain, W. J. and Brody, J. S. (1972). Effect of growth hormone on post-pneumonectomy lung regeneration. American Review of Respiratory Disease, 105, 1003.

Chatrath, R. R., El Shafie, M., and Jones, R. S. (1971). Fate of hypoplastic lungs after repair of congenital diaphragmatic hernia. Archives of Disease in Childhood, 46, 633.

Davies, G. M. and Reid, L. (1970). Growth of the $\frac{\rho}{\Phi}$ alveoli and pulmonary arteries in childhood. Thorax, 25, 669. 
Dunnill, M. S. (1962a). Quantitative methods in the study of pulmonary pathology. Thorax, 17, 320.

Dunnill, M. S. (1962b). Postnatal growth of the lung. Thorax, 17, 329.

Emery, J. L. and Mithal, A. (1960). The number of alveoli in the terminal respiratory unit of man during late intra-uterine life and childhood. Archives of Disease in Childhood, 35, 544.

Henderson, R., Hislop, A., and Reid, L. (1971). New pathological findings in emphysema of childhood: 3. Unilateral congenital emphysema with hypsplasia-and compensatory emphysema of contralateral lung. Thorax, 26, 195.

Hislop, A. (1971). The Fetal and Childhood Development of the Pulmonary Circulation and its Disturbance in Certain Types of Congenital Heart Disease. Ph.D. Thesis, University of London.

Hislop, A. and Reid L. (1970). New pathological findings in emphysema of childhood. 1. Polyalveolar lobe with emphysema. Thorax, $25,682$.

Hislop, A. and Reid, L. (1972). Intra-pulmonary arterial development during fetal life-branching pattern and structure. Journal of Anatomy, 113, 35 .

Hislop, A. and Reid, L. (1973). Pulmonary arterial development during childhood: branching pattern and structure. Thorax, 28, 129.

Kitagawa, M., Hislop, A., Boyden, E. A., and Reid, L. (1971). Lung hypoplasia in congenital dia- phragmatic hernia. A quantitative study of airway, artery, and alveolar development. British Journal of Surgery, 58, 342.

Liggins, G. C. and Howie, R. N. (1972). A controlled trial of antepartum glucocorticoid treatment for prevention of the respiratory distress syndrome in premature infants. Pediatrics, 50, 515.

Ryland, D. and Reid, L. (1971). Pulmonary aplasiaa quantitative analysis of the development of the single lung. Thorax, 26, 602.

Snyder, W. H. J., Jr and Greaney, E. M., Jr (1965). Congenital diaphragmatic hernia: 77 consecutive cases. Surgery, 57, 576.

Weibel, E. R. (1963). Morphometry of the Human Lung. Springer, Berlin.

Wohl, M. E. B., Griscom, N. T., Schuster, S. R., Zwerdling, R. G., and Strieder, D. (1973). Lung growth and function following repair of congenital diaphragmatic hernia. Pediatric Research, 7,424 .

Requests for reprints to: Professor Lynne Reid, Department of Experimental Pathology, Cardicthoracic Institute, Brompton Hospital, London SW3 6HP. 